\title{
Collecting suicide statistics for the severely mentally ill
}

\author{
Riadh T. Abed
}

Since the Heam of the Nation government document (Departiment of Hecith, 1992) set the larget for the rectuction of sulcide in the severely mentally if by $33 \%$ by the year 2000 it has become neceseary to collect the suicide data for this population of pationts at district and netiond bevel. There are a ranges of problems conceming the definition and identification of patients with severe mented thness as well os problems concerning the compillation of suleids data for this popertation at distilet lovel.

\section{Problems with definition and identification of the severely mentally ill}

Despite the fact that the reduction of suicide linked to severe mental illness (SMI) by 33\% by the year 2000 was one of three targets for mental health, the Mental Illness Key Area Handbook (DoH, 1993) gave no specific criteria for the identification of this condition. However, it offered general guidelines through stating that the decision that someone has a severe and enduring mental lllness ". . . is a judgement made on the basis of severity and duration of symptoms and disability which may lead patients to have severe social problems because of their inability to cope with ordinary living. This inability to cope might necessitate repeated or lengthy admissions or day care attendance, sheltered accommodation, or long-term medication". Although the 1994 edition of the Handbook (DOH, 1994) gave a number of more detailed, research-based options, it conceded that there was no widely agreed definition for SMI and suggested that locally agreed definitions may be reached 'pragmatically'. Furthermore, it quite rightly warned against using diagnostic groups as a means of identifying the SMI population.

It is understood that the Health of the Nation outcome scales are expected to contribute to the formulation of a definition of SMI. However, until this becomes available, districts may consider using one or more of the existing registers as a means of assessing the suicide rates within this population.

\section{Option 1}

One option is to define SMI as anyone who has had contact with psychiatric service. In every district there is a computerised database that contains a range of demographic and other data and offers easy access to more extenstve data through the psychiatric casenotes. Such a database will have been in existence in some form in 1990, the baseline year for the suicide reduction target.

However, there are some disadvantages. These include the fact that not all those who have been in contact with psychiatric services are severely mentally ill. This is especially true for patients who have had single or very short-term episodes of care or those who may have had more longterm treatment for circumscribed psychiatric disorders but are otherwise able to live normal productive and personal lives. Furthermore, it is likely that some of the severely mentally 111 may be treated exclustvely at the primary care level and would therefore not appear on the psychiatric register.

A further issue is that of comparability between districts. Although differences in referral patterns to psychiatric services between districts should not be great, differences may arise due to administrattve decisions regarding who is or is not registered as a psychiatric patient. For example local practices vary regarding the registration of self-harm patients who are seen once by a psychiatrist and discharged back to their GPs.

\section{Option 2}

Another option would be to use one or more of the statutory registers already in exdstence for the purpose of identifying the severely mentally ill. The avallable registers include the Care Programme Register (CPR). The Section 117 Register and the Supervision Register.

The CPR was established in Aprll 1991 and was initially understood to include those psychiatric patients with particularly chronic or severe illness who are likely to require intenstve support in the community. However, it has always been possible to include any patient who is accepted by specialist mental health services'. More 
recently, in the 1994 Handbook, the CPR has been subdivided into three tiers requiring high, medium and low mental health support, thereby practically encompassing all patients who come in contact with psychiatric services for whom some therapeutic intervention is offered. The high dependency group may also be on the Supervision Register which is meant for those who are at particular risk to themselves, at risk of selfneglect or a risk to others.

The Supervision Register and the Section 117 Register are likely to include small numbers of SMI patients and will not be representative of the population of the severely mentally ill within a district.

However, the use of the CPR to identify the severely mentally ill for the purpose of monitoring suicide rates can present certain problems. These may include:

(a) patients may be able to remove their names from the register (although this may not be possible if the register is simply incorporated into the register for mental health patients within the district):

(b) the register was not in existence in 1990 and therefore it is not possible to use it for the purpose of obtaining a baseline figure;

(c) a further problem is the point in time when the register is considered to have reached a 'steady state' and is judged to be representattve of the SMI population for that district. It has been our experience in Rotherham that such a register can take a couple of years before reaching such a state.

However, the new tiered CPR recommended by the second edition of the Handbook may offer a more reliable register of psychiatric patients. The entry level into the register requires only that a patient is accepted for treatment by the specialist mental health service and recetves treatment from any member of the team. Although this is still clearly overinclusive it is an improvement on the district register of total psychiatric contact as it excludes patients who have been seen once and discharged back to their GPs, i.e. where no intervention is offered.

Also, this clear criterion is likely to improve reliability across districts.

\section{Determining the suicide rate for the severely mentally ill}

The suicide rate (national or local) for the SMI population for the year 1990 is unknown.
Also, no figures can be collected at local level until such time as a nationwide agreement takes place regarding who is to be considered as severely mentally ill. As pointed out above, all existing registers (except registers for all psychiatric contact) date after 1990 and there are potential problems of comparabllity across districts. A further potentially serious problem is the issue of the reliability of the suicide figures relating to such small populations as the severely mentally ill within a health district.

The Handbook recognises that the annual suicide figures for the general population of a district are likely to show large fluctuations and it therefore recommends that five year rolling averages should be used to reduce such fluctuations. The document goes on to suggest that the average for the years 1986-90 is used as a baseline figure for the suicide rate within the general population of a given district. If this is the case for large district size populations (the smallest district in England is just over 100000 in population), the fluctuation will be a much greater problem for the suicide figure for the severely mentally ill that is likely to be in the region of several hundred up to several thousand in total depending upon the size of the district and the definition of SMI. This being the case it would appear that the problem of the annual fluctuation of the suicide figures for the SMI will be difficult or even impossible to remedy.

\section{Conclusion}

Any definition of SMI will have to be applied in a uniform manner across the country for meaningful comparisons to be made between districts. One suggestion would be that the new Care Programme Register (all tiers) is used as an interim definition of SMI.

\section{References}

DEPARTMENT OF HEALTH (1992) Health of The Nation: A Strategy of Health for England. London: HMSO.

- (1993) Key Area Handbook, Mental Miness. London: HMSO.

- (1994) Key Area Handbook. Mental Mliness. (2nd edn). London: HMSO.

Riadh T. Abed, Consultant Psychiatrist, Department of Psychiatry, Rotherham District General Hospital, Moorgate Road, Rotherham S60 2UD 